\title{
Strategy of Product Development and Process of Creative Industries in Indonesia
}

\author{
Ryan Kurniawan, Andhi Sukma \\ Faculty of Business and Management \\ Universitas Widyatama \\ Bandung, Indonesia
}

\author{
Evo Sampetua Hariandja \\ Business School, Department of Management \\ Universitas Pelita Harapan \\ Tangerang, Indonesia \\ evo.hariandja@uph.edu
}

\begin{abstract}
Creative industries in Indonesia are confronting the globalization pressures that is profoundly focused and to maintain their prosperity by new product development. The target of this study was investigating the activity of product development by including strategy, process, organization, the performance assessment of new product development itself. This study led through the survey that have utilized already with changes balanced with attributes of Indonesia creative industries and interview with manager and director level of product planning, product engineering, product development, marketing planning, and $R \& D$. The sample in this study are 320 creative companies consisting $25 \%$ private, $15 \%$ SME, $10 \%$ joint venture, $10 \%$ home industry, and the rest were others. The results revealed that $51 \%$ of product development strategy comes from the direction of top management and $47 \%$ from outsiders. Mostly the objective of product development in order to meet consumer demand. The strategy of product development of creative industries in Indonesia were new products that emphasize on derivative products.
\end{abstract}

Keywords-product development, process, creative industry, Indonesia

\section{INTRODUCTION}

Creative industries are contributing a sum of $7.2 \%$ of GDP and $9 \%$ of export value in 2010 . The capability of the creative industries is a main priority of the government through the Ministry of Trade, with the objective of $8 \%$ of GDP for 2011 and additionally expanding total export value to $12 \%$ by 2015 . The creative industry is exceedingly assorted split extensively more than 15 industry classifications including advertising, fashion, design, music and software development. Fashion remains the predominant sub-area of the creative industry in Indonesia as far as commitment to GDP at $63.3 \%$ for 2010 took after by crafts at $33.2 \%$. The part is comprised of a large number of SMEs at an expected $6.74 \%$ of aggregate companies in Indonesia and is a noteworthy wellspring of new entrepreneurial among the nation's youth. Commitment to exports expanded by more than 35\% from 2006 to 2010 (Ministry of Trade) which is great considering its relative curiosity as a business sub-division. New product development is analogous to climbing high peaks and steep cliffs, challenging, invigorating, and empowering experience of the people involved. To be able to successfully climb to the top of the cliff, we require a set of tools, neatly arranged plan, and team support each other and work together using a set of these tools when necessary in due course. Successful new products also require a process that is well planned and mature (1). Team that varies background of diverse disciplines must work in unison to the direction in which the product will be brought and through the Fuzzy Front End process to create products that meet the needs, wants, and desires of consumers. Within the company, new product development is an integrated part of the company's strategic plan. Within the company, new product development is an integrated part of the company's strategic plan. In (2), Ansoff and Steward, classify the four strategies of product development as follows: first-to-market, follow-the-leader, me-too, and application engineering.

In (3), stated that the product development process becomes more specialized and dynamic as well as the need to change for the better. The products produced by the company are always moving towards dynamic to satisfy the needs of consumers. Overall new product development is the core engine of growth companies. Therefore, the company is required expertly manage it. As the rapidly changing market in accordance with the development and competitive conditions which are no longer so easy as times past, the companies in Indonesia, especially those engaged in the creative industry are required also to move more quickly in order to satisfy what the consumer desires. A comprehensive study conducted by Information Resources Inc. (IRI) in 2000 showed that of the 21 categories of packaged goods are launched to the market, $52 \%$ failed (4). These results prove that the new product development requires the right strategy together with the supporting aspects such as human, infrastructure, culture, and continuous innovation. The Creative Industry Mapping Study which has been directed by the Department of Trade of Republic of Indonesia on 2008, embraced the creative business definition from UK DCMS Task Force 1998 so that the creative business in Indonesia can be characterized as: "The industry originating from the inventiveness, aptitudes and also singular interest use to make the thriving and the work occupation by the creation and utilization of innovative and individual creation powers". In light of the definition, the Department of Trade in the study gathered and set 15 economic activities sorted as the Creative Industry as follows: Advertisement; Architecture; Art and Antique Market; Craft Design; Fashion Design; Video, Movie 
and Photography; Interactive Game; Music; Performing Arts; Publication and Printing; Computer and Software Services; Television and Radio; Research and Development; and Culinary.

To be able to survive in the market, the company is always trying in various ways to stay ahead of its competitors by creating a very new product, different process, utilizing the infrastructure of the same or different, requiring new skills, launch derivative products to save costs or to creating a product that was radical/breakthrough. New product development is inseparable from the role of top level management pattern top-down or bottom-up depending on how the innovation process to produce those products. In creating products, innovation plays an important role, especially in terms of the effect on the habits and consumer behavior with minor or major effect and competencies and complementary assets of the company with its increase or completely destroy. The innovation consists of incremental, major, strategic, and radical (5). Indonesia's creative industry at this time to face the level of competition and a great challenge, especially in the ability to create new products as an indicator of success or failure in generating cash and influence the minds of consumers. If not careful, then the chance to win the competition can be detached. Comparative advantage as an indicator of success is no longer a back-bone in winning the battle in the world of business that requires high intensity and concentration. Innovation and design are keys to win the competition in the era of creative economy now. Innovations in the development of new products and services becomes key to how large companies can survive and also offset with the process that continually improve the ability and competence on the other. The study of the indicators of success of new product development in Indonesia has not done particularly telescoped creative industry. For it is very good and gives a direct impact for companies creative for more than learn what the main indicators in the successful development of new products. This study is intended as a learning arena and to contribute in terms of improving Indonesia's competitiveness in the global arena. The focus of this study is based on the strategy and process applied by the company in the development of new products.

\section{LITERATURE REVIEW}

The new product development (NPD) writing underlines the significance of presenting new products available for proceeding with business achievement. Its commitment to the development of the organizations, its impact on benefit execution, and its part as a key component in business planning have been all around archived (6); (7); (8); (9); and (10). New products are in charge of business, financial development, innovative advancement, and high standard of living. Consequently, the study of NPD and the process through which they rise is vital.

The NPD procedure comprises of the exercises completed by firms when creating and dispatching new products. A new product that is presented on the market advances over a succession of stages, starting with an underlying product idea or thought that is assessed, created, tried and propelled on the market (6). This arrangement of exercises can likewise be seen as a progression of data social occasion and assessment stages. As a result, as the new product advances, administration turns out to be progressively more educated (or less indeterminate) about the product and can evaluate and reassess its underlying choice to embrace development or dispatch. Tailing this procedure of data social occasion and assessment can prompt enhanced new product choices with respect to firms by restricting the level of danger and minimizing the assets focused on products that in the long run fizzle. The NPD procedure contrasts from industry to industry and from firm to firm. Surely it ought to be adjusted to every firm keeping in mind the end goal to meet particular organization assets and requirements (6). Numerous analysts have attempted to build up a model that catches the significant phases of the NPD procedure (10); (11); (9); (7); (12). Various NPD models have been created throughout the years, the best known of which is the (6) model, appeared in Figure 1 , otherwise called the BAH model, which underlies most other NPD frameworks that have been advanced. This broadly perceived model seems to envelop the greater part of the essential phases of models found in the writing. It depends on broad reviews, top to bottom meetings, and contextual investigations and, thusly, has all the earmarks of being a genuinely decent representation of winning practices in industry.

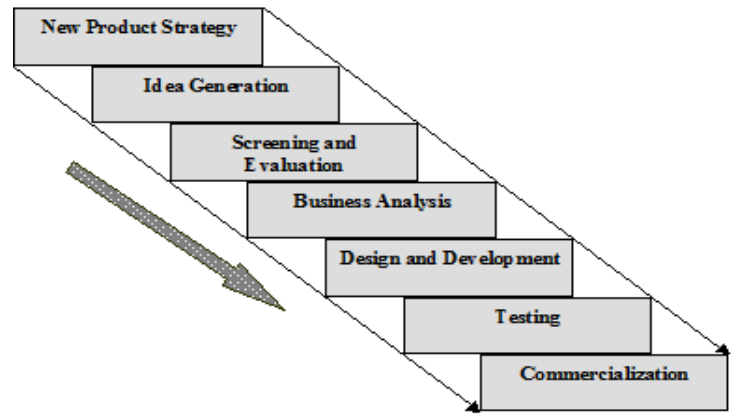

Figure 1. Stages of NPD

Development of new products, as the main activity in the innovation process in the company has been seen by many researchers as a key factor of success. In (13), believe that new product development is the key to success, growth and prosperity in the modern enterprise. Refer to (14) also has the same opinion, the new product is vital for companies to be able to survive for a long time.

\section{METHODOLOGY}

Focus of this study on the creative industry in Indonesia from micro, small, medium and large, The ownership in the form of private, domestic investment, FDI, and Joint Venture. Categorization of types of new products refers to research conducted in (15) includes derivative products, platforms, and radical. The variables in this study were measured through a questionnaire that has been adopted by (16) and some modifications to adjust the characteristics of the creative industry in Indonesia and also from literature related to new product development. 
The number of samples obtained from this study is 320 companies. Of the 320 companies are grouped into different types, namely: advertisement, architecture, arts and antique market, craft, design, fashion design, video, movie and photography, interactive game, music, performing arts, publication and printing, computer and software services, television and radio, research and development and, culinary. Distributing questionnaires covering centers of industrial area in West Java, DKI Jakarta and Banten. Distribution of the questionnaires carried out by first making contact with the parties directly involved with new product development process in the company. The parties are authorized in this case consists of a manager level up to director level with the field directly related such as: marketing, product engineering, $\mathrm{R} \& \mathrm{D}$, product planning, product development, design, and fields that have a direct link with the development of new products.

\section{RESULTS}

\section{A. Respondent Profile}

Types of creative industries covered in this study consisted of $40 \%$ of culinary, $24 \%$ advertisement, $22 \%$ fashion design, $4 \%$ design, $4 \%$ interactive game, $3 \%$ craft, and $3 \%$ video, film and photography. Creative industry coverage obtained in this study has been adequately described the creative industry forum in Indonesia. From preliminary observations also showed that the creative industry is all that goes into the Directory of Creative Industry Classification from Department of Trade incorporated into this study. This is due to there are some companies that the research samples do not have divisions and departments of product development, product engineering, product planning, or research and development. Only companies that have divisions and departments mentioned above are targeted for this study. This profile is shown in Figure 2 below.

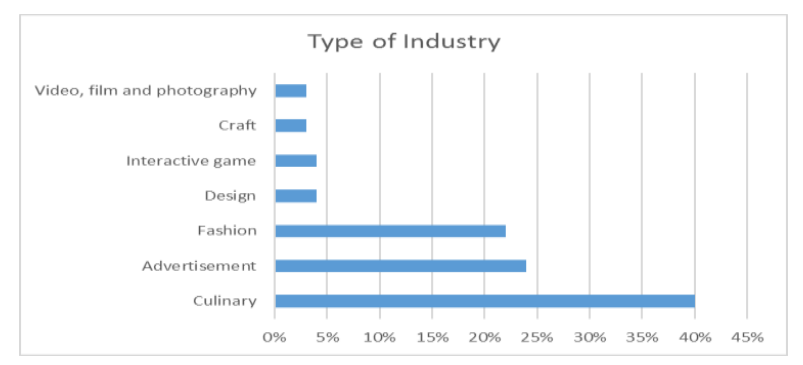

Figure 2. The type of industry

From data processing result that the size of the company there are $33 \%$ of companies are classified as micro, $32 \%$ small companies, $30 \%$ medium-sized companies, and $2 \%$ of large enterprises as shown in Figure 3 where the data size of the company's group already represents the characteristics of the size of the creative industry located in West Java, DKI Jaya and Banten.

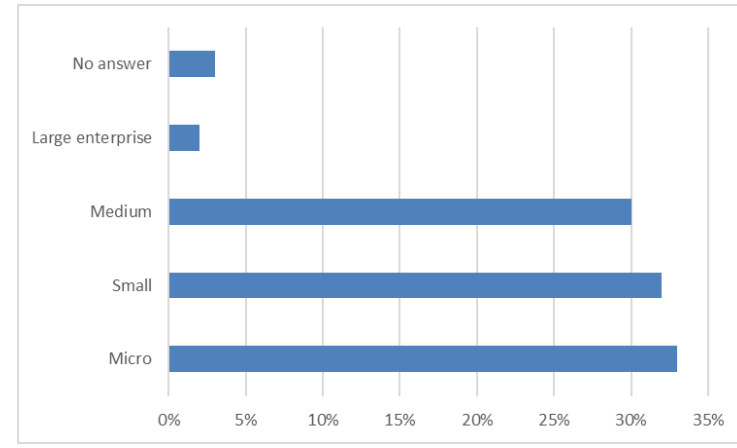

Figure 3. Type of company

From the type of ownership of the company is shown in Figure 4 below, the profile of respondents consisted of others $40 \%$, $19 \%$ private, joint venture $12 \%$, small and medium enterprise (SME) 12\%, home industry $9 \%$ and CV $8 \%$. From this data it appears that private and others type of ownership showed high participation in the study and spread largely.

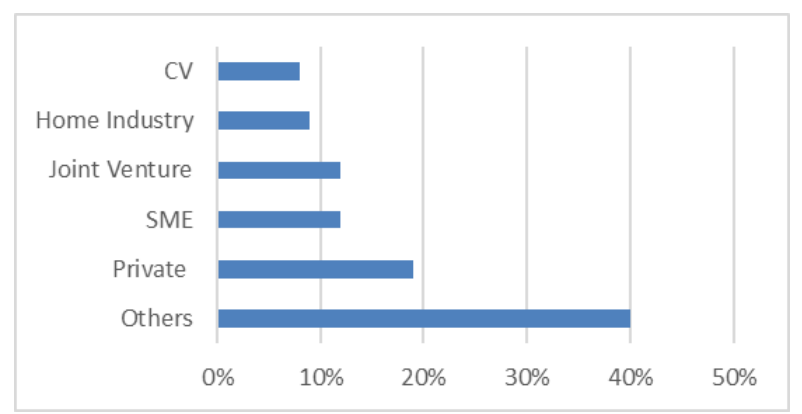

Figure 4. Type of Ownership

From the total number of permanent employees, most distributions in the range of companies with a number of employees between 1-99 peoples to contribute 93\%, while companies classified as large of number of employees is only $7 \%$ as shown in Table 1.

Table 1. Total of permanent employee

\begin{tabular}{|c|r|}
\hline Total Permanent Employee & $\%$ \\
\hline $1-19$ & $87 \%$ \\
\hline $20-99$ & $9 \%$ \\
\hline $100-250$ & $3 \%$ \\
\hline $251-500$ & $1 \%$ \\
\hline
\end{tabular}

Another characteristic that is reflected in the survey of new product development is the scope of the company's business area conducted by the respondent. As many as $79 \%$ of companies making sales in the country, and the rest is exported to various countries dominated by Asian countries $(21 \%)$. It is quite encouraging, because it means that the products that manufactured by the creative industry in Indonesia has a market not only in the country but also abroad, given the fairly competitive business competition. 


\section{B. New Product Development Process}

The total sample of 320 companies, however, only $60 \%$ of companies have a formal procedure for new product development, while the rest $42 \%$ conduct new product development process in the absence of formal procedures, nor did new product development altogether. In R\&D activities $44 \%$ done in domestic, $31 \%$ do not done, $17 \%$ no answer, and $8 \%$ done in overseas and outsourcing. The market survey activity done in domestic market by $64 \%$ companies, $19 \%$ do not done, $4 \%$ combination in domestic and overseas market, and the rest is combination between outsourcing and overseas. From identification of product idea, $65 \%$ done in domestic and the rest is combination between do not done and no answer. The product concept selection has done in domestic market by $69 \%$ companies and $6 \%$ in overseas. From the total respondents, $69 \%$ agrees the concept selection conducted in Indonesia as domestic market.

\section{New Product Development Strategy}

Approximately $21 \%$ do not agree that the company considers the products developed are not entirely new. This suggests that in order to be able to compete in a highly competitive market, companies are required to provide differentiation to the product made by a company before. For the process to create a new product in the company, 36\% support the different processes on the contrary $20 \%$ did not indicate approval. In terms of creating new products $28 \%$ more support for the use of the new process and vice versa $54 \%$ do not support. This proves that not all products are produced and provide differentiation require different processes and tools from the previous. It is influenced by factors of assets, efficiency, infrastructure, and funds needed, and also depends on the scale of the company and scope of its operations. The ability to compete with the processes and limited infrastructure is very heavy in this competitive era. The company strives to conduct its operations with a high degree of efficiency but on the one hand should be able to adapt to the needs of its customers.

From factors new skills required to make the product, $56 \%$ support that product development requires new skills to be able to produce a quality product, different, and received by the market. Product development strategy undertaken by the company, over $44 \%$ of respondents companies are trying to follow a strategy of first-to-market by developing products that did not exist on the market before. This strategy requires a budget that does little and marketing efforts to create innovative products. If seen from product development strategy based on derivatives/derivative, then companies in West Java, DKI Jaya, and Banten tend to look for opportunities to try to develop a product that does not exist in the market but by following the flow of the previous product with the same platform. This strategy is executed with the aim to save costs and maintain existing networks with more and more using the same components, but still provide differentiation (17).
The ability of innovation to create breakthrough products that are classified/radical, firms in West Java, DKI Jaya and Banten still have to learn more to global companies. The study shows that only $24 \%$ of companies that support that they produce a product that was radically contrary to the market and $43 \%$ do not support this. It shows that the innovation process is not running too fast and still requires conduces shape and ride. This fact requires creative companies in West Java, DKI Jaya and Banten should be more instrumental to try something new compared to the existing one. Refer to (18), stated that effective product development is not achieved simply by increasing the cost of $\mathrm{R} \& \mathrm{D}$, relies on technology radical or introducing tools and new techniques but a pattern consistent overall view of the system of total development includes organizational structure, technical skills, process completion issues, culture and strategy. The consistencies not only work in broad system architecture but also in the level of detailed work.

New product development cannot be separated from the pattern found in the company's leadership and culture growing in it. Strong leadership can provide the vision, mission and a clear direction in the development of new products. The study shows that in the development of new products, the top two-boxes $51 \%$ is agree that always directed by the top management. For the proposed development of new products, top two-boxes $47 \%$ of respondents always get it from outsiders. From this study, showed results that are new product development begins with the top-down pattern but proposals outside parties in this case not only consumers but could be other parties involved with the company holding a significant portion. In the economy of creative, sources of ideas from different layers. The involvement of all parties in the development of new products should be the concern of all parts in good company with the pattern of top-down, bottom-up, peer-to-peer, inside-out, or outside-in.

The study conducted on the creative industry in Indonesia as shown in Table 2, shows that of the entire development of new products made by the company, $73.45 \%$ aim to meet consumer demand. Followed by improving quality $(61.06 \%)$, creating new markets $(55.75 \%)$, and follow the industry's trend $(46.02 \%)$. Extend product life cycle $(40.02 \%)$ the next sequence as the company's goal to develop new products, followed by the product diversification $(23.01 \%)$. Following the decreasing production cost was selected by $15.04 \%$ of respondents and only $14.06 \%$ who chose to apply the new technology. In this item of questionnaires, the respondent given the preference to choose more than one option. The results of this study support the fact that occur in a competitive era now that satisfy consumer demand to the company goals in order to survive. In (19), stated that the essence of a business is to create customer, customer, and customer. This is in line with the statement of Drucker. 
Table 2. The objective of new product development

\begin{tabular}{|l|c|}
\hline \multicolumn{1}{|c|}{$\begin{array}{c}\text { The Objective of new product } \\
\text { development }\end{array}$} & $\%$ \\
\hline Fulfilling consumer's demand & $73.45 \%$ \\
\hline Improving product quality & $61.06 \%$ \\
\hline Create new market & $55.75 \%$ \\
\hline Follow the trend in industry & $46.02 \%$ \\
\hline Extend product lifecycle & $40.02 \%$ \\
\hline Product diversification & $23.01 \%$ \\
\hline Decrease production cost & $15.04 \%$ \\
\hline Application of new technology & $14.16 \%$ \\
\hline
\end{tabular}

The development of new products require no small cost compared to the cost for other activities such as marketing, production, customer retention, and others. Table 3 below shows the allocation of the budget required by the company's $\mathrm{R} \& \mathrm{D}$ activities.

More than $51 \%$ of creative companies in West Java and DKI Jaya province spend R \& D budget is only around 0\%$9 \%$ of its annual sales and the rest $46 \%$ around $10 \%-20 \%$ of annual sales. This resulted in the introduction of new products merely derivative products alone, rarely can produce radicals that are highly loaded with technology and requires considerable cost. New product categories radical, global, technology-based differentiation and future trends have not been part of creative industry in West Java and DKI Jaya. Required commitment, consistency, and coherence to achieve successful performance of new products and qualified.

Table 3. Budget allocation for R\&D

\begin{tabular}{|l|r|}
\hline The average of R\&D budget & $\%$ \\
\hline $0-4 \%$ & $27 \%$ \\
\hline $5-9 \%$ & $24 \%$ \\
\hline $10-14 \%$ & $36 \%$ \\
\hline $15-19 \%$ & $10 \%$ \\
\hline No answer & $3 \%$ \\
\hline
\end{tabular}

Allocation of funds $\mathrm{R} \& \mathrm{D}$ in the company would be different, depending on the industrial subsector, the number of people involved, the duration of the new product development project, the size of the company and the company's strategy. Studies have shown that in general, the manufacturing industry in Indonesia is quite minimal in allocating funds for R \& D activities of the company. The lack of funds allocated to R \& D activities showed that the company's commitment to developing new products is not too high.

The company only innovating "moderation" and not willing to create a new product that is "better" than they are today, which is really something different than exist today. In addition, the funds will be minimal causing part of $\mathrm{R} \& \mathrm{D}$ can't make the necessary technology investments to be able to create new products that can compete in the market. Another impact of fund allocation of R \& D activities is at least a new product development project that is able to be financed by the company. Thus, not surprisingly, the creatives industry in Indonesia will produce a new product which is quite small. If the company want to survive in an increasingly competitive global market, it must allocate a larger R \& D so that the ability to conduct research and development of products can be increased, which led to the emergence of innovative products.

Studies conducted in the creative industry in West Java, DKI Jaya, and Banten shows that type of newly developed products leads to derivative products as shown in Table 4.

Table 4. Type of New product

\begin{tabular}{|l|c|}
\hline Variable & Point out of 5 scale \\
\hline Derivatives products & $4.35 / 5.00$ \\
\hline Produk breakthrough/radikal & $2.55 / 5.00$ \\
\hline
\end{tabular}

Associated with the low funding of R \& D as described previously, it is not surprising that the type of new products produced by the creatives industry in Indonesia leads to derivatives, where the product developed a modification / improvement of existing products today, which was developed to meet the needs of consumers. This supports previous findings that the biggest new product development goals are performed by the industry is to meet consumer demand.

Derivative products have the feature shorter life cycle and low margin aiming to survive in a competitive and saturated market. This is in contrast with breakthrough products/radicals are able to create new markets with high margins, but require resources far greater. Type of derivative products are generally developed by the creative industry in West Java, DKI Jaya and Banten resulted in the product does not produce a significant increase in profit due to its low margin. Although it has different advantages and disadvantages, but these products are relatively the same as competitors. Consumers are sensitive to the comparison between the costs and benefits (cost and benefit) will carefully compare the price to be paid by the benefits. The relatively short life cycle that caused the company to be able to launch new products in a fairly short time anyway.

Therefore, in order to maintain and increase corporate profits, the creative industry in West Java, DKI Jaya and Banten should begin to direct the development of new products towards products that radical. With the launch of this type of product, even the company will be able to create new markets, because of the unavailability of solutions for consumers prior to the product. Data collected from respondents indicated that the creative industry in West Java and DKI Jaya is characterized by a low number of new products were successfully launched into the market. A total of $52 \%$ of the total respondents launched less than nine products each year as shown in Table 5. 
Table 5. Total of new product launch

\begin{tabular}{|c|c|}
\hline Total of new product launch & Percentage \\
\hline $0-4$ & $35 \%$ \\
\hline $5-9$ & $17 \%$ \\
\hline $10-14$ & $18 \%$ \\
\hline $15-19$ & $6 \%$ \\
\hline$\geq 20$ & $23 \%$ \\
\hline
\end{tabular}

The low number of new products were successfully launched indicates that the creative industry in West Java, DKI Jaya and Banten province is not active in the business development of a new product or process innovation. These conditions need to be wary of considering the development of new products is a key factor of success to be able to compete in today's business world. With a low number of products launched, it is feared that someday the industry will not be able to survive against the onslaught of new products emerging from abroad, such as China, Malaysia and Vietnam.

However, the small numbers of new products related to the allocation of $\mathrm{R} \& \mathrm{D}$ funds are quite small. This resulted in new product development part only able to do research and development in very limited quantities, so that not many products succeed. Other factors that affect the least number of successful new products launched include the time required and the quality of human resources. As mentioned previously, the time required to complete the new product will be very different depending on the sub-sector of the industry as well as the difficulty of process in idea and manufacture. The more complicated the process of making a product, and then the time required will be longer. This process can be accelerated by the mastery of technologies that will help people in doing research and product development.

The qualities of human resources in the creative industry in three provinces that will either encourage the emergence of new products are innovative. With the level of expertise and skills and always up-to-date on the latest knowledge, the new range of products can be born. The low number of new products were successfully launched by the creative industry in three provinces (less than 9 products) around 52\%, may mean that the quality of human resources available to date does not support the creation of new products. Companies with foreign ownership would prefer to offices in other countries are considered to have a better quality of human resources to conduct research and development of new products. In fact, to be able to have the skills in this field, human resources have to implement it, so the quality will improve little by little. If the quality of human resources is not corrected, then the new products produced by the creative industry in West Java will not increase, and they will only do process alone, according to the new products that have been developed elsewhere. Developing a product requires the allocation of resources and the strategy of the company in accordance with the character of the products of the company, as well as the impact on the market of the product to be developed. Figure-4 below shows how the relationship between the characteristics of the products that will be developed on the changing nature of the technology of these products and their impact on the market, which is based on the framework of Aggregate Project Planning (APP).

APP framework, can be used as a tool for connecting between corporate strategies is used, with a mechanism of allocating the company's resources in product development projects. Handling of new product development in the creative industry in the company must be aligned with the goal of short-term and long-term. Product development must be an integral part of business strategy in order to achieve the desired profit and growth. Innovation as an important part of business strategy is the reason why the company should have clear rules of procedure regarding the implementation of new product development. This is to ensure that the process is running properly, so that the evaluation and improvement can be easily done.

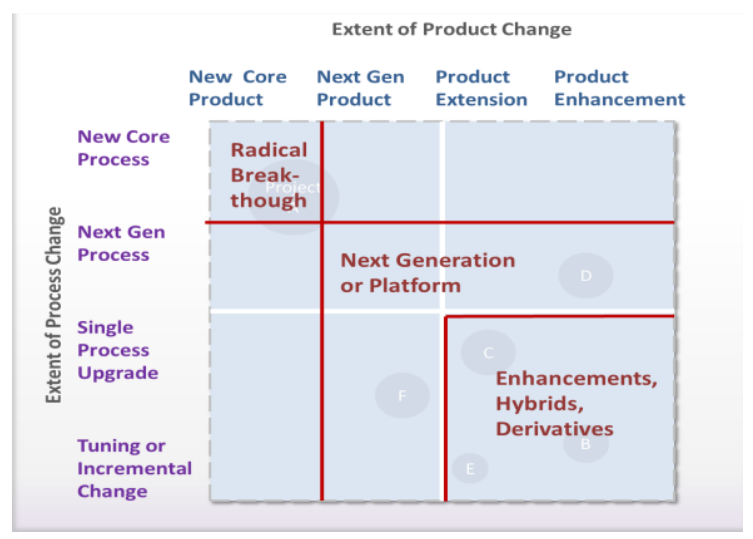

Fig. 4. Aggregate Project Planning Framework (APP) Source: Wheelwright and Clark (1992)

The existence of a formal procedure in the development of new products becomes important to know whether there are stages that have been executed properly. In addition, it is important for the purposes of the evaluation process, which the company can determine the role and the time required from the relevant sections to complete the task, and analyze the results of the development of new products. The above findings show that more than half of the creative industry in Indonesia realizes the importance of the development of new products by having and running a formal procedure. By having these procedures, new product development process can take place effectively and efficiently, so that the time required to develop new products can be shorter. In developing new products, $44 \%$ stated that new product development is done by serial, $27 \%$ combination, and $19 \%$ concurrent.

In general, it can be seen that the new product development process in the creative industry in Indonesia has a tendency to be serialized. With these properties, it is not surprising that the new product development process is slow and takes longer, because the proposals or new product ideas cannot be directly realized if there is still a long unresolved activity. Any problems that arise in the process of 
development of new products will be returned to the responsible in the previous process. As a result, the solution of these problems is likely to be completed within a longer time, so that when the product is launched into the market, the company will lose momentum and competitors may have taken advantage by being first in the market.

\section{CONCLUSIONS}

Focus of the creative industries in West Java, DKI Jaya, and Banten in product development is meeting the consumer's needs as key factors in the application strategy rests on the development of a new product category with a budget derived relatively not too large compared to the annual sales of the company as well as the direction of top-level management significantly. In order to produce a radical, differentiation, advanced technology, requires a large budget in research and development as well as commitment and consistency coupled with the creation of a conduces environment and innovative organization and collaboration with those universities as research centers and government institutions.

From the above analysis, some conclusions can be drawn as follows:

-In applying the new product development strategy, the company is responsive to the market. Wishes and market changes is a major trigger in determining the direction of new products development.

-The creative industry in West Java, DKI Jaya, and Banten province was marked by the launch of a new product level is low and $52 \%$ of companies stated only have less than nine new products every year, with a focus on derivatives and not radical (breakthrough).

-More than half of companies only allocate less than $9 \%$ of annual sales to fund R \& D activities

-Initiatives to develop new products generally come from the direction of the top level management and also from outside.

-This study stated that $58 \%$ of companies have formal procedures in new product development, but does not have a special unit to handle this event, where $16 \%$ stated that the activity is not have the autonomous unit and $28 \%$ held by department marketing and collaborate with another department.

-Part of marketing a greater role in providing and determine new product ideas, while the $\mathrm{R} \& \mathrm{D}$ is instrumental in realizing the idea became feasible to produce. Part of production tends to play a passive role, merely implementers.

-In terms of the performance of new products, the implementation of new product development to benefit the company, both internally and externally.

To obtain better results, further studies should involve also creative companies outside West Java, DKI Jaya, and Banten that have center of gravity for creative community such as Yogyakarta, Bali, Central Java, East Java, Sumatra, Kalimantan, and Sulawesi with samples of diverse creative industries. It also required further study on the innovation performance and innovation culture of creative industry in Indonesia to see the differences in the indicators used in the development of new products in terms of strategy, processes, organization, and performance evaluation.

\section{REFERENCES}

[1] Cagan J, Vogel CM. Creating breakthrough products: Innovation from product planning to program approval: Ft Press; 2002.

[2] Morse LC, Babcock DL. Managing Engineering and Technology: An Introduction to Management for Engineers: Prentice Hall; 2010.

[3] Reinertsen D. Let It flow: how lean product development sparked a revolution. Industrial Engineer. 2005;37(6):40-6.

[4] Schneider J. NEW PRODUCT LAUNCH: Stagnito communications ББК: У842. 0-36, 0; 2004.

[5] Markides C, Geroski P. Fast second how smart companies bypass radical innovation. US: Jossey-Bass; 2005.

[6] Booz A. Hamilton (1982) New Product Management for the 1980's Booz, Allen \& Hamilton. Inc, New York. 1982.

[7] Crawford CM. New Product Failure Rates-a Reprise. Research management. 1987;30(4):20-4

[8] Urban Glen L, Hauser John R. Design and marketing of new products. Prentice Hall, Englewood Cliffs, NJ; 1993.

[9] Cooper RG. Winning at New Products: Accelerating the Process from Idea to Launch (Создание успешных продуктов: ускорение процесса от возникновения идеи до выхода на рынок). 2001.

[10] Ulrich K, Eppinger S. Product design and development, McGrawHill/Irwin. New York, NY. 2011

[11] Wind Y. Product policy: concepts, methods, and strategy: AddisonWesley; 1982.

[12] Scheuing EE. New product management: Dryden Press; 1974

[13] Shepherd C, Ahmed PK. NPD frameworks: a holistic examination. European Journal of Innovation Management. 2000;3(3):160-73.

[14] Ozer M. Information technology and new product development: opportunities and pitfalls. Industrial Marketing Management. 2000;29(5):387-96.

[15] Wheelwright SC, Clark KB. Revolutionizing product development: quantum leaps in speed, efficiency, and quality: Simon and Schuster; 1992.

[16] Goldense BL, NPDP C, CPIM C, Needham M. Concurrency. 2007.

[17] Hariandja ES, Kautsar AW. Strategi Perusahaan dalam Pengembangan Produk Baru: Penelitian Kasus Perusahaan Manufaktur di Indonesia. INASEA. 2007;8(1):58-68

[18] Clark KB, Fujimoto T. Product development performance: Strategy, organization, and management in the world auto industry: Harvard Business Press; 1991.

[19] Drucker PF. Classic Drucker: essential wisdom of Peter Drucker from the pages of Harvard Business Review: Harvard Business Press; 2006 